\title{
Condrodisplasia em bovinos no Sul do Rio Grande do Sul ${ }^{1}$
}

\author{
Ana Carolina B. Coelho' ${ }^{2}$, Clairton Marcolongo-Pereira ${ }^{2}$, Mauro Pereira Soares ${ }^{3}$, \\ Pedro de Souza Quevedo ${ }^{2}$, Franklin Riet-Correa ${ }^{4}$ e Ana Lucia Schild ${ }^{3 *}$
}

\begin{abstract}
Coelho A.C.B., Marcolongo-Pereira C., Soares M.P., Quevedo P.S., Riet-Correa F. \& Schild A.L. 2013. [Chondrodysplasia in cattle in Southern Brazil.] Condrodisplasia em bovinos no Sul do Rio Grande do Sul. Pesquisa Veterinária Brasileira 33(10):11951200. Laboratório Regional de Diagnóstico, Faculdade de Veterinária, Universidade Federal de Pelotas, Campus Universitário s/n, Pelotas, RS 96010-900, Brazil. E-mail: alschild@terra.com.br

Fourteen cases of chondrodysplasia in cattle are described. Epidemiological and clinical data were obtained from filed necropsy protocols. A histological study of the lesions was performed on long and skull base bones. Eleven cases of chondrodysplasia Telemark type and three Bulldog (Dexter) type were observed. Thirteen out of 14 cases occurred in Jersey cattle and one in Shorthorn. It was concluded that the gene carrier of chondrodysplasia is present in the Jersey population of the region, and breeding measures such as the use of bulls from other regions and/or progeny testing or identification of undesirable genes using molecular techniques should help reduce the occurrence of these cases in the Jersey population of the region.
\end{abstract}

INDEX TERMS: Chondrodysplasia, Dexter, Telemark, dwarfism, bulldog, skeletal dysplasia.

RESUMO.- Descrevem-se 14 casos de condrodisplasia em bovinos. Os dados epidemiológicos e clínicos foram obtidos de protocolos de necropsia e o estudo histológico das lesões foi realizado em fragmentos de ossos longos e ossos da base do crânio dos 14 casos estudados. Onze casos eram de condrodisplasia tipo Telemark e três, tipo bulldog (Dexter). Treze dos 14 bovinos afetados eram da raça Jersey e um era da raça Shorthorn. Concluiu-se que o gene transmissor das condrodisplasias encontra-se presente na população Jersey da região e medidas, como utilização de reprodutores de outras regiões e/ou com teste de progênie ou identificação de genes indesejáveis por meio de técnicas moleculares, devem contribuir para diminuir a ocorrência destes casos na população Jersey da região.

TERMOS DE INDEXAÇÃO: Condrodisplasia, Dexter, Telemark, nanismo, bulldog, displasia esquelética.

\footnotetext{
${ }^{1}$ Recebido em 17 de julho de 2013.

Aceito para publicação em 2 de setembro de 2013.

${ }^{2}$ Programa de Pós-Graduação em Veterinária, Faculdade de Veterinária, Universidade Federal de Pelotas (UFPel), Campus Universitário s/n, Pelotas, RS 96010-900, Brasil

${ }^{3}$ Laboratório Regional de Diagnóstico, Faculdade de Veterinária, UFPel, Pelotas, RS. *Autor para correspondência: alschild@terra.com.br

${ }^{4}$ Hospital Veterinário, Centro de Saúde e Tecnologia Rural (CSTR), Universidade Federal de Campina Grande (UFCG), Patos, PB 58700-000, Brasil.
}

\section{INTRODUÇÃO}

Condrodisplasia (dwarfism, nanismo) é uma malformação congênita de transmissão hereditária na maioria dos casos, caracterizada pelo desenvolvimento anormal da cartilagem de crescimento intersticial (ossificação endocondral) dos ossos longos que resulta no crescimento longitudinal anormal e diminuído dos ossos, sendo reconhecida como uma das mais frequentes malformações observadas no homem e nos animais (Crew 1924, Latter et al. 2006, Thompson 2007). Apresenta-se em duas formas básicas, o nanismo proporcional e o nanismo desproporcional, sendo que nesta última forma as apresentações fenotípicas são variadas e classificam-se, com base em suas características morfológicas, em tipo bulldog (Dexter), tipo Telemark, tipo snorter (braquicefálico) e tipo cabeça alongada (dolicocefálico) (Thompson 2007). As diversas formas deste defeito são observadas em várias raças bovinas incluindo a Dexter (Harper 1998), Telemark (Thompson 2007), Holandês (Naito et al. 2002, Thompson 2007), Aberdeen Angus, Hereford e Shorthorn (Mishra, 2004), Jersey, Guernsey, Ayrshire e Charolês (Gregory et al. 1951, Thompson 2007). Nanismo proporcional hereditário foi diagnosticado em rebanhos da raça Angus na Austrália (Latter et al. 2006).

Condrodisplasia do tipo Telemark transmitida por um gene recessivo autossômico simples tem sido identificada nas raças Holandês (Naito et al. 2002), Nganda, Guernsey e 
Jersey (Thompson 2007). A condição foi descrita, também, em bovinos Hereford no Canadá, atribuída à alimentação das fêmeas com pastagem ou silagem de trevo (Ribble et al. 1989). Na Austrália surtos da doença afetando bovinos das raças Murray Grey, Hereford e Angus ou suas cruzas ocorreram durante dois anos consecutivos, sendo sugerida a deficiência de manganês como a causa mais provável (McLaren et al. 2007). A apresentação desta forma da doença caracteriza-se pelo encurtamento e rotação dos membros, cabeça redonda e maior que o normal, focinho curto, braquignatia e fenda palatina. Na raça Jersey esta condição tem sido observada com uma grande variação fenotípica (Thompson 2007).

A forma mais severa das condrodisplasias em bovinos, a do tipo bulldog ou Dexter, ocorre nas raças Dexter e Holandês e possivelmente também nas raças Charolês e Jersey (Thompson 2007). Esta forma da doença está bem documentada na raça Dexter (Cavanagh 2007) e tem sido associada a um gene de dominância incompleta que em homozigose é letal (Harper et al. 1998, Thompson 2007). No Rio Grande do Sul dois casos de condrodisplasia do tipo bulldog foram relatados recentemente, sendo um caso em bovino Jersey (Wurster et al. 2012). 0 padrão característico inclui o aborto, nanismo desproporcional, coluna vertebral curta, marcada micromelia, cabeça grande e focinho curto, fenda palatina, protrusão da língua e presença de uma grande hérnia abdominal com exposição das vísceras (Harper et al. 1998).

As lesões histológicas no tipo Telemark caracterizam-se basicamente pela redução e irregularidade na zona de hipertrofia do disco epifisário, com desordenamento das colunas de condrócitos. Espaços císticos multifocais podem estar presentes na zona hipertrófica e entre condrócitos degenerados ou calcificados na zona de mineralização sugerindo falha na formação da matriz ou perda prematura dos condrócitos e da matriz (McLaren et al. 2007). No tipo bulldog os ossos, muito reduzidos de tamanho, caracterizam-se histologicamente pela perda da diferenciação do disco epifisário, observando-se um acúmulo desordenado de condrócitos e uma matriz fibrilar circundando vasos sanguíneos. Há defeituosa calcificação endocondral nas placas epifisárias e redução no comprimento dos ossos longos (Harper et al. 1998, Agerholm et al. 2004, Thompson 2007). Há presença de osteoclastos, a esponjosa primária está desorganizada e há reabsorção irregular da cartilagem na esponjosa primária (Harper et al. 1998).

Os objetivos deste trabalho foram relatar 14 casos de condrodisplasia diagnosticados no Laboratório Regional de Diagnóstico (LRD) da Universidade Federal de Pelotas (UFPel) entre os anos de 1978 e 2012, bem como descrever os aspectos epidemiológicos e clínico-patológicos desta malformação, avaliando sua importância econômica para a região.

\section{MATERIAL E MÉTODOS}

Foram revisados nos arquivos do LRD/UFPel os protocolos de necropsias realizadas e/ou de materiais enviados por veterinários de campo que atuam em municípios da área de influência do laboratório, identificando-se os casos de condrodisplasia diagnos- ticadas em bovinos entre 1978 e 2012. Desses protocolos foram resgatados os dados referentes à idade, ao sexo, à raça, à procedência e ao quadro clínico-patológico. Os dados epidemiológicos, o manejo utilizado nas propriedades e as alterações macroscópicas observadas em cada caso foram obtidos nos protocolos de necropsia e no acervo fotográfico do LRD. 0 estudo histológico das lesões foi realizado no fêmur e úmero, nos ossos da base do crânio e nas vértebras em cada caso existente no arquivo de materiais do LRD, os quais haviam sido conservados em formalina tamponada a $10 \%$.

Fragmentos de diáfise e epífise dos ossos longos, dos ossos da base do crânio e dos corpos vertebrais fixados foram descalcificados em solução de ácido clorídrico e ácido fórmico a 8\% na proporção de 1:1 durante um período de aproximadamente 14 dias, embebidos em parafina e cortados com $5 \mu \mathrm{m}$ de espessura. Os cortes foram corados com hematoxilina e eosina (HE) e tricrômico de Masson (TM) para avaliação histológica em microscópio ótico.

\section{RESULTADOS}

Entre os anos de 1978 e 2012 foram observados 11 casos de condrodisplasia tipo Telemark (Fig.1) e três casos de condrodisplasia tipo bulldog (Dexter) (Fig.2A-C) que representaram $29,16 \%$ dos defeitos congênitos e doenças hereditárias diagnosticados em bovinos no LRD/UFPel no período. Todos os bovinos afetados eram provenientes de municípios da região Sul do Rio Grande do Sul. Treze casos ocorreram na raça Jersey em propriedades de exploração leiteira e um na raça Shorthorn.

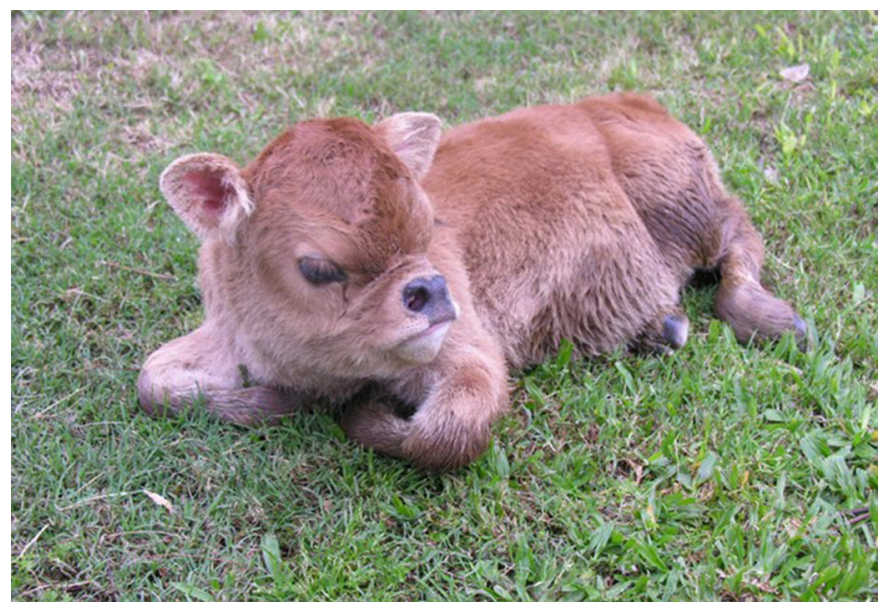

Fig.1. Condrodisplasia tipo Telemark. O bezerro apresenta crânio arredondado, focinho achatado e orelhas pequenas. Os membros estão torcidos impedindo o animal de permanecer em estação.

Nos três casos diagnosticados como condrodisplasia tipo bulldog os bovinos afetados eram da raça Jersey e foram abortados em torno dos sete meses de gestação e eram provenientes de propriedades de exploração leiteira. Nos casos de condrodisplasia tipo Telemark o tempo de sobrevivência dos bovinos afetados variou de 1-90 dias, sendo que o bovino que sobreviveu por 90 dias conseguia manter-se em estação e andar e foi alimentado durante o período de sobrevivência. 0 resumo dos dados epidemiológicos e o tipo de condrodisplasia diagnosticado em cada caso são apresentados no Quadro 1. 

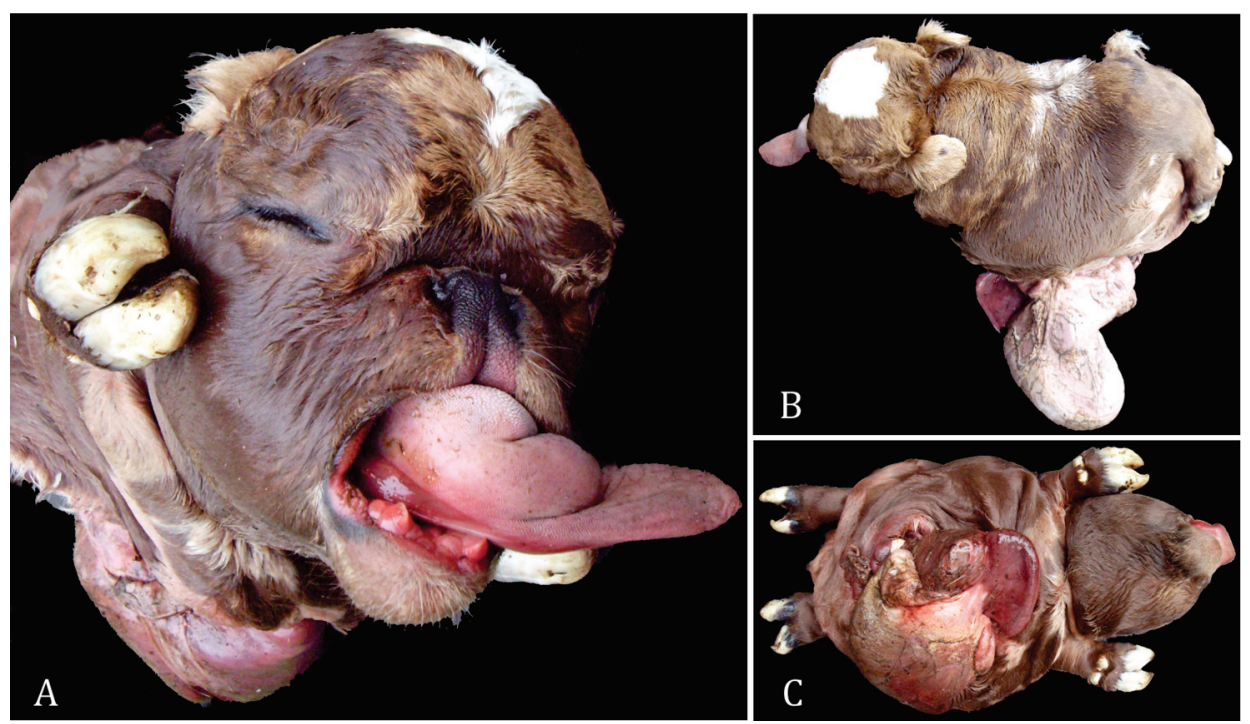

Fig.2. Condrodisplasia tipo bulldog. (A) Há malformação de todo o corpo do bezerro que apresenta cabeça desproporcionalmente grande e redonda, com o focinho achatado, a língua protrusa e malformação dos dentes. (B) Vista dorsal mostrando lordose, micromelia e pescoço curto. (C) Vista ventral mostrando grande hérnia umbilical com exposição das vísceras e micromelia.

Quadro 1. Casos de condrodisplasia observados em bovinos na região sul do Rio Grande do Sul entre 1978 e 2009

\begin{tabular}{|c|c|c|c|c|c|c|}
\hline $\begin{array}{l}\text { Bovino } \\
\text { no. }\end{array}$ & Data & Raça & Idade & Município & Exploração & $\begin{array}{l}\text { Tipo de condro- } \\
\text { displasia }\end{array}$ \\
\hline 1 & $12-03-1980$ & Jersey & 10 dias & $\mathrm{Ni}^{*}$ & Leiteira & Telemark \\
\hline 2 & 19-03-1981 & Jersey & Natimorto & Pelotas & Leiteira & Telemark \\
\hline 3 & 21-07-1981 & Jersey & Aborto & Morro Redondo & Leiteira & Bulldog \\
\hline 4 & 30-11-1982 & Jersey & 1 dia & Pelotas & Leiteira & Telemark \\
\hline 5 & $13-10-1983$ & Jersey & 3 dias & Pelotas & Leiteira & Telemark \\
\hline 6 & 16-11-1983 & Jersey & 10 dias & Pelotas & Leiteira & Telemark \\
\hline 7 & $17-12-1984$ & Jersey & Natimorto & Pelotas & Leiteira & Telemark \\
\hline 8 & 28-12-1985 & Jersey & $\mathrm{Ni}$ & Pelotas & Leiteira & Telemark \\
\hline 9 & 06-02-1986 & Jersey & $\mathrm{Ni}$ & Pelotas & Leiteira & Telemark \\
\hline 10 & 04-09-1996 & Shorthorn & Natimorto & Dom Pedrito & Corte & Telemark \\
\hline 11 & 05-02-1998 & Jersey & 3 meses & Capão do Leão & Leiteira & Telemark \\
\hline 12 & 01-06-1999 & Jersey & aborto & Pinheiro Machado & Leiteira & Bulldog \\
\hline 13 & $17-07-2007$ & Jersey & aborto & Pelotas & Leiteira & Bulldog \\
\hline 14 & 04-10-2007 & Jersey & 6 dias & Pedro Osório & Leiteira & Telemark \\
\hline
\end{tabular}

Todos os bovinos com diagnóstico de condrodisplasia tipo Telemark apresentavam malformações caracterizadas por nanismo desproporcional. A cabeça era arredondada e maior do que o normal e o focinho curto (Fig.1). Havia exoftalmia, lordose e a inserção da cauda era mais alta do que em bezerros normais. Em alguns casos havia protrusão da ponta da língua. Os membros eram curtos e torcidos na maioria dos casos impedindo que os animais permanecessem em estação (Fig.1). Em alguns casos havia, também, aumento da mobilidade das articulações metacarpo-falangenas com extensão exagerada das mesmas. Todos os bovinos apresentavam fenda palatina. 0 corte sagital da cabeça revelou os ossos da base do crânio curtos com as cartilagens articulares espessas e irregulares comparados aos de um bovino controle da mesma raça e idade (Fig.3A-D). 0 fêmur, o úmero e as vértebras eram, também, mais curtos e largos quando comparados aos de um bovino controle.

Nos três bovinos com diagnóstico de condrodisplasia tipo bulldog (Dexter) as alterações macroscópicas eram similares e acentuadas. Os corpos eram pequenos em relação a fetos normais de mesma idade, a cabeça era grande e arredondada e o focinho achatado, havia protrusão completa da língua (Fig.2A). Havia, ainda, braquignatia, ausência do palato duro, malformação dos dentes que estavam voltados para fora Dorsalmente observava-se o pescoço curto e micromelia (Fig.2B,C). Havia, também, hérnia abdominal com exposição das vísceras (Fig.2C). 0 esqueleto revelou a acentuada desproporção entre a cabeça e o restante do corpo (Fig.4). Os ossos dos membros eram severamente malformados curtos, estreitos nas diáfises e unidos por um tecido não mineralizado que desapareceu na digestão dos tecidos moles (Fig.4). 

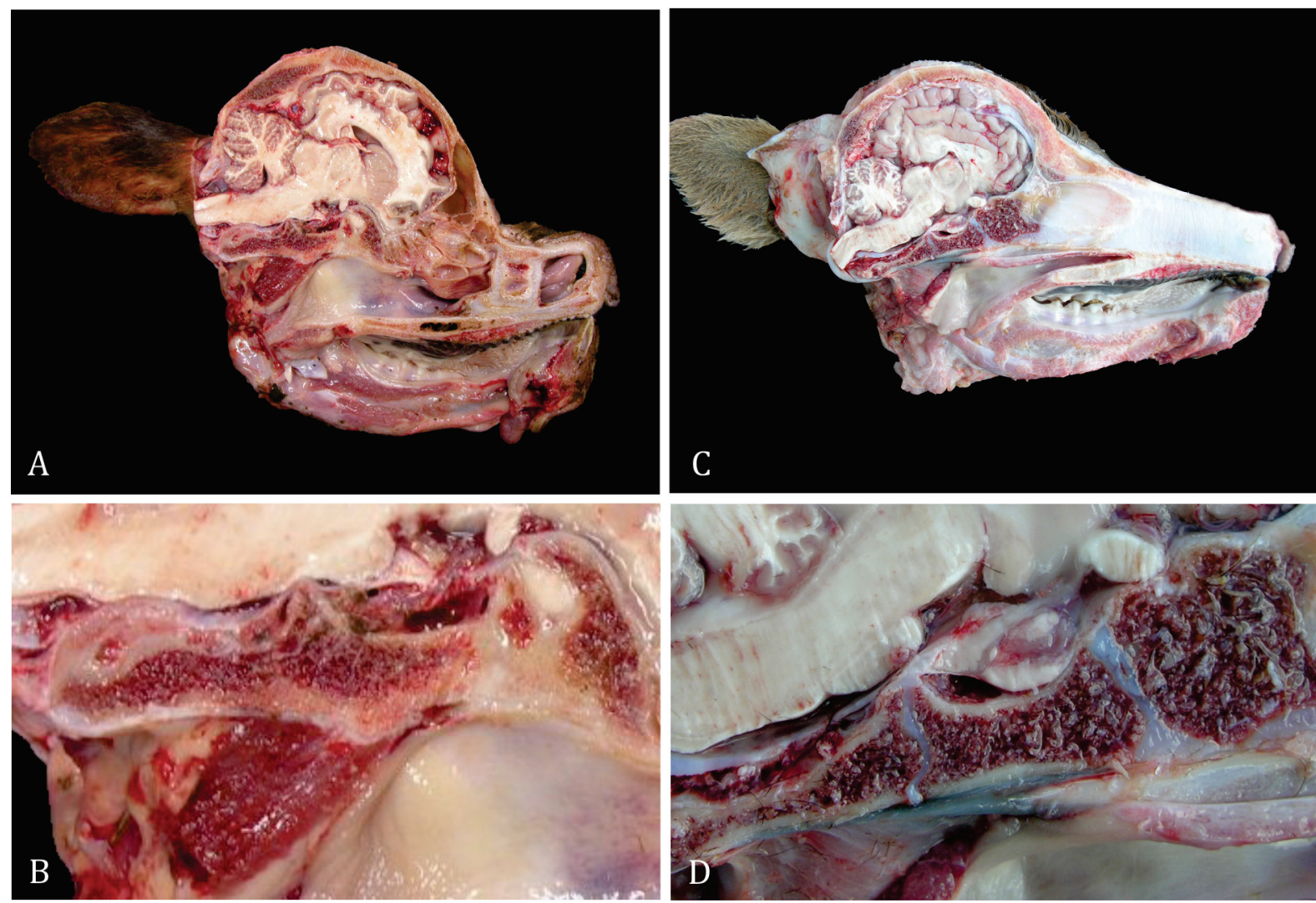

Fig.3. (A) Corte sagital da cabeça de um bezerro com condrodisplasia tipo Telemark. 0 crânio é arredondado e o focinho curto. (B) Os ossos da base do crânio são menores e a as cartilagens articulares espessas e irregulares. (C) Corte sagital da cabeça de um bezerro controle. (D) Ossos da base do crânio do bezerro controle

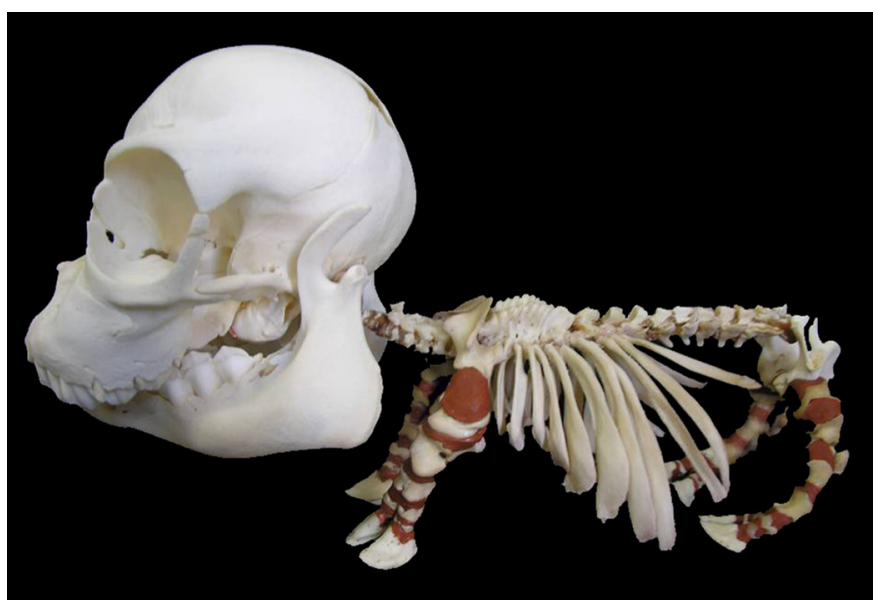

Fig.4. Esqueleto de bezerro com condrodisplasia tipo bulldog evidenciando o crânio desproporcionalmente grande em relação ao restante do corpo, malformação das costelas e coluna vertebral. Os ossos de membros são muito curtos com a região da diáfise mais estreita e mineralizada. As porções de cor avermelhada correspondem a massa utilizada para montar o esqueleto.

As lesões histológicas observadas nos bovinos afetados por condrodisplasia tipo Dexter caracterizaram-se por ossos longos apresentando a placa epifisária desorganiza- da formando um aglomerado denso de condrócitos sem a diferenciação entre as zonas. As metáfises eram curtas e as trabéculas espessas com calcificação deficiente (Fig.5),

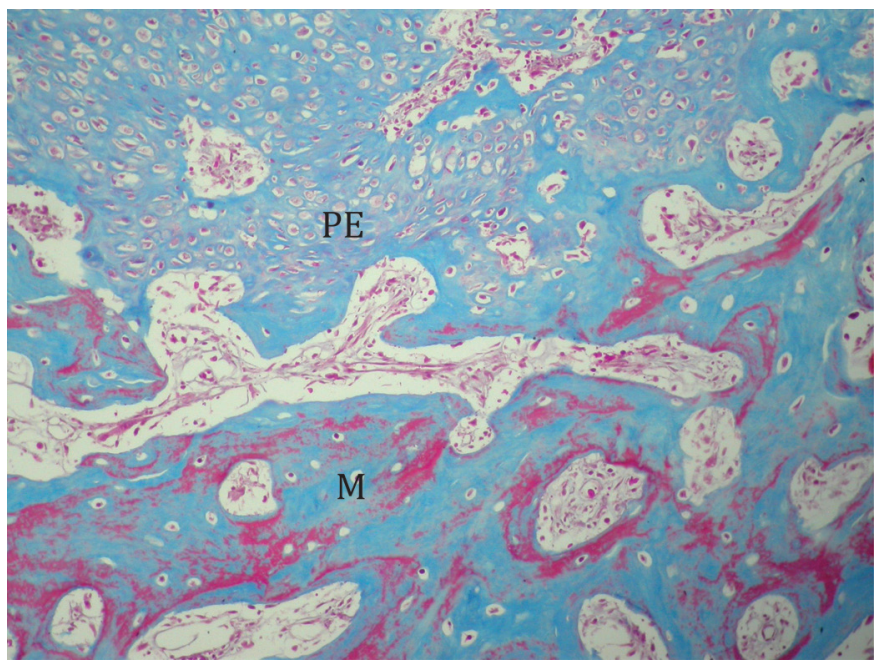

Fig.5. Epífise/metáfise do fêmur de bezerro com condrodisplasia tipo bulldog. A placa epifisária (PE) está desorganizada formando um aglomerado denso de condrócitos sem a diferenciação entre as zonas. A metáfise (M) é curta e as trabéculas são espessas com calcificação deficiente (TM 20x). 
quando comparadas as epífeses/metáfises de um bezerro da mesma raça que nasceu morto e foi utilizado como controle (Fig.6A). Nos casos de condrodisplasia tipo Telemark as placas epifisárias dos ossos longos apresentavam a zona hipertrófica irregular e reduzida com colunas desordenadas variando marcadamente em número e alinhamento ao longo da placa epifisária (Fig.6B). A zona proliferativa não estava evidenciada na placa epifisária (Fig.6B). A esponjosa primária era formada por trabéculas curtas e irregulares (Fig.6B).

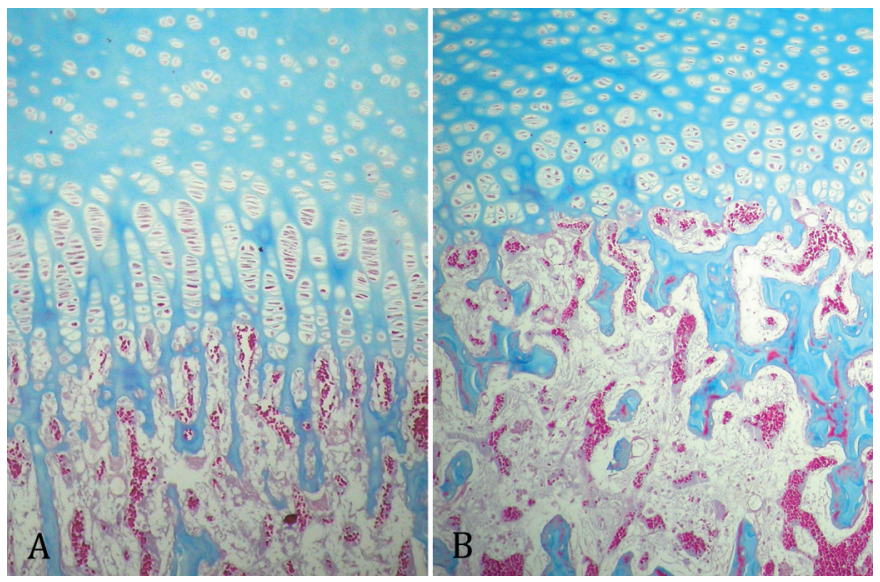

Fig.6. (A) Epífise/metáfise de fêmur de bezerro controle. (B) Epífise/Metáfise do fêmur de bezerro com condrodisplasia tipo Telemark. A placa epifisária apresenta a zona hipertrófica irregular e reduzida com colunas desordenadas variando marcadamente em número e alinhamento. Não há zona proliferativa. A esponjosa primária é formada por trabéculas curtas e irregulares (TM20x).

\section{DISCUSSÃO}

As condrodisplasias foram os defeitos congênitos mais frequentemente diagnosticados em bovinos no LRD/UFPel entre os anos de 1978-2012, correspondendo, aproximadamente, a um terço de todos os casos de malformações congênitas observadas em bovinos neste período. 0 diagnóstico da condição foi realizado pelos aspectos clínico-patológicos observados nos bezerros afetados.

Onze dos 14 casos foram classificados como condrodisplasia do tipo Telemark, que tem sido descrita na raça Jersey como uma condição hereditária transmitida por um gene recessivo autossômico (Thompson 2007). Em todos estes 11 casos os bovinos afetados eram da raça Jersey, provenientes de pequenas propriedades de exploração leiteira da região sul do Rio Grande do Sul, o que parece confirmar que o gene indesejável está presente na população dessa raça na região. Um trabalho de levantamento de defeitos congênitos em ruminantes na região sul do Rio Grande do Sul menciona que a consanguinidade é favorecida em pequenos estabelecimentos de exploração leiteira da região pelo uso de um mesmo reprodutor por vários anos (Marcolongo-Pereira et al. 2010). Um bovino afetado era da raça Shorthorn, tratando-se possivelmente, de um caso esporádico sem causa definida. Nanismo em bovinos de corte foi observado em animais alimentados em pastagem de trevo e silagem embora a causa do defeito não tenha sido determinada (Ribble et al. 1989). Na Austrália, também em bovinos de corte, a enfermidade foi atribuída à severa deficiência congênita de manganês (McLaren et al. 2007).

Condrodisplasia do tipo bulldog foi observada em três oportunidades também em bovinos da raça Jersey. Esta malformação é descrita nas raças Dexter e Holandês sendo transmitida por um gene de dominância incompleta que quando em homozigose produz uma condição congênita letal (Harper et al. 1998), existindo uma suposição de que pudesse ocorrer na raça Jersey (Thompson 2007). Dois casos, sendo um nesta raça foram relatados recentemente no Rio Grande do Sul (Wurster et al. 2012). A condição está associada à mutação no gene que codifica o aggrecan (ACAN) que é o principal proteoglicano presente nas cartilagens articulares sendo fundamental na morfogênese do condroesqueleto durante o desenvolvimento fetal (Kiani et al. 2002). 0 fato de que as alterações fetais nos casos de condrodisplasia tipo bulldog são muito semelhantes em todos os relatos (Harper et al. 1998, Agerholm et al. 2004, Cavanagh et al. 2007, Wurster et al. 2012) sugere que a patogenia da malformação seja idêntica nas diferentes raças bovinas em que a doença foi observada. As lesões histológicas observadas nos animais deste estudo foram similares às encontradas por outros autores que descreveram casos de condrodisplasias (Harper et al. 1998, McLaren et al. 2007, Thompson 2007), demonstrando também, que independentemente da etiologia não há muita variação no padrão de lesão histológica.

Por outro lado, nos casos de condrodisplasia tipo Telemark as variações fenotípicas observadas nos bezerros afetados são frequentes observando-se desde animais com rotação total dos membros e impossibilidade de manter-se em estação até casos de bezerros que conseguem mamar e seguir suas mães (McLaren et al. 2007). Nos casos observados no sul do Rio Grande do Sul um bezerro afetado sobreviveu durante 90 dias, entretanto deve ser considerado que neste caso o animal era incapaz de alimentar-se sozinho e que provavelmente teria morrido com poucos dias de vida se não recebesse auxilio.

\section{CONCLUSÃO}

O gene responsável pelas condrodisplasias ocorre na população Jersey da região Sul do Estado. Medidas como utilização de reprodutores de outras regiões e/ou teste de progênie ou identificação de genes indesejáveis por meio de técnicas moleculares devem contribuir para diminuir a ocorrência destes casos na população Jersey da região.

\section{REFERÊNCIAS}

Agerholm J.S., Arnbjerg J. \& Andersen 0. 2004. Familial chondrodysplasia in Holstein calves. J. Vet. Diagn. Invest. 16:293-298.

Cavanagh J.A.L., Tammen I., Windsor P.A., Bateman J.F., Savarirayan R., Nicholas F.W. \& Raadsma H.W. 2007. Bulldog dwarfism in Dexter cattle is caused by mutations in ACAN. Mamm. Genome 18:808-814.

Crew F.A.E. 1924. The Bull-dog Calf: A Contribution to the Study of Achondroplasia. Proc. R. Soc. Med. 17(Sec. Comp. Med.):39-58. 
Crew F.A.E. 1924. The Bull-dog Calf: A Contribution to the Study of Achondroplasia. Proc. R. Soc. Med. 17(Sec. Comp. Med.):39-58.

Gregory P.W., Rollins W.C., Pattengale P.S. \& Carrol F.I. 1951. A phenotypic expression of homzygousDwarfis in beef cattle. J. Anim. Sci. 10:922-933.

Harper P.A.W., Latter M.R., Nicholas F.W., Cook R.W. \& Gill P.A. 1998. Chondrodysplasia in Australian Dexter cattle. Aust. Vet. J. 76(3):199-202.

Kiani C., Chen L., Wu Y.J., Yee A.J. \& Yang B.B. 2002. Structure and function of aggrecan. Cell Res. 12(1):19-32.

Latter M.R., Latter B.H.D., Wilkins J.F. \& Windsor P.A. 2006. Inheritance of proportionate dwarfism in Angus cattle. Aust. Vet. J. 84(4):122-128.

Marcolongo-Pereira C., Schild A.L., Soares M.P., Vargas Jr S.F. \& Riet-Correa F. 2010. Defeitos congênitos diagnosticados em ruminantes na Região Sul do Rio Grande do Sul. Pesq. Vet. Bras. 30(10):816-826.

McLaren P.J., Cave J.G., Parker E.M. \& Slocombe R.F. 2007. Chondrodysplastic calves in Northeast Victoria. Vet. Pathol. 42:342-354.
Mishra B.P. 2004. Indentifying genetic cause of dwarfism in American Angus cattle. Iowa State University Animal Industry Report. A.S. Leaflet R1870, on line.

Naito K., Maruyama M., Dobaschi K., Tanimura N., Kimura K., Haritani M. \& Nakajima Y. 2002. Congenital chondrodysplastic dwarfism with dyshematopoiesis in a Holstein calf. J. Vet. Med. Scie. 64(10):937-939.

Ribble C.S., Janzen E.D. \& Proulx J.G. 1989. Congenital join laxity and dwarfism: A feed-associated congenital anomaly of beef calves in Canada. Can. Vet. J. 30:331-338.

Thompson K. 2007. Bones and joints, p-1-184. In: Maxie M.G. (Ed.), Jubb, Kennedy, and Palmer's Pathology of Domestic Animals. Vol.1. $5^{\text {th }}$ ed. Saunders Elsevier, Philadelphia.

Wurster F., Bassuino D.M., Juffo G.D., Boos G.S., Boabaid F.M., Antoniassi N.A.B. \& Driemeier D. 2012. Condrodisplasia tipo Dexter em fetos bovinos abortados. Acta Scient. Vet. 40(3):1060-1064. 